\title{
Innovations in Machining
}

\author{
Komarov V. A* \\ Professor, doctor of technical Sciences, Russia.
}

\begin{abstract}
*Corresponding Author: Komarov V. A, Professor, doctor of technical Sciences, Russia.
\end{abstract}
\begin{abstract}
For more than 40 years, I have been working to improve the efficiency of manufacturing critical parts of machines, devices and devices by improving the cutting process. I am the author of a new impulse cutting theory. Based on the proposed theoretical provisions of the new pulse cutting theory [1,2], new laws are proposed that link the parameters of accuracy and rigidity of the system: machine-tool-tool-workpiece, as well as elements of the tool design and cutting modes with the wear of the cutting material and the quality of the treated surface.

They also allow you to choose the material grade of its cutting part, coating and cutting modes that provide maximum performance with the greatest wear resistance of the tool; provide the required surface roughness, commensurate with the finish (RA $\leq 0.16$ microns). The proposed theoretical propositions suggest further development of the energy method and, in this regard, new quantitative dependencies that are derived not on the basis of empirical coefficients, but on the basis of theoretical calculations of design, technological and physical parameters. The use of dependencies allows processing of surfaces (including high-hard ones) with high accuracy and finishing effect in one technological transition. Significantly reduces the complexity of manufacturing and the cost of additional equipment.
\end{abstract}

Keywords: Cutting, tool, pulse cutting theory, cutting modes, drilling, milling, threading

\section{INTRODUCTION}

For more than 40 years I have been engaged in research in the field of machining. As a result, it was found that the nature of the destruction of almost any solid structural materials, including stones, ceramics, artificial chemical compounds (plastics), various metals and alloys, composite materials, etc., having a homogeneous plastically elastic medium has a pulse, oscillatory character [1].

On the basis of the conducted researches regularities were received and the new impulse theory of cutting [1] which use allows to conduct processing of surfaces of any materials at achievement of high accuracy and effect of finishing for one technological transition is created.

1. Significantly reduces the complexity of manufacturing and the cost of additional equipment.

2. Manage the wear of both known, standard tools and newly designed, calculating and setting the optimal cutting conditions for the processing of any structural materials, even those that do not yet exist!

Examples of specific implementation:

\section{THREADING}

Changing the design of the cutting part of the nut tapping taps and small modernization of machines, with the establishment of new design cutting modes in 2000. at the Oryol steel Rolling plant (SPZ) allowed, when threading nuts: M6*1, M8*1.25, M16*2 (material STEEL 20) to obtain the following results: productivity increased by 1.5-2 times; durability of taps from 4-10 times. Thread accuracy increased by 2 qualit(accuracy of threads obtained by standard tool H6, our design H4).

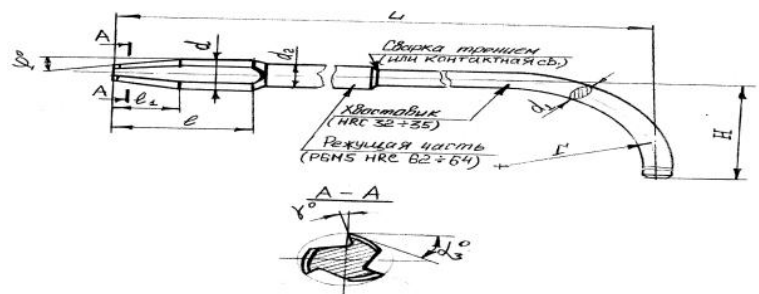

Fig.2 


\section{Titanium Alloy Processing High-Speed Cutting of W-8 Titanium Alloy}

In 2001, at the production facilities of NIAT, was implemented experimental high-speed machining of titanium alloys (VT-6, VT-8).In milling operations, the allowance of 4-7 $\mathrm{mm}$ was removed per pass. the cutting Speed, depending on the diameter of the cutter, was $28 \mathrm{~m} / \mathrm{s}$ and $45 \mathrm{~m} / \mathrm{s}$. The roughness of the treated surface $\mathrm{Ra}=0.1$ microns. Drilling of layered material - titanium - carbon fiber - titanium with a drill of special design F10mm was carried out. The task of high-performance drilling without chips of carbon fiber was performed.

\section{DRY TREatment OF FUSible Aluminum Alloys}

In 2002, the laboratory of the University of physics and technology mgupi-GM, carried out dry processing of samples from cast aluminum alloys brands AK6M2, US 319 and US 380;

a) drilling of aluminum alloy AK6M2, US 319 and US 380 with hard alloy drills of Kennametal design.

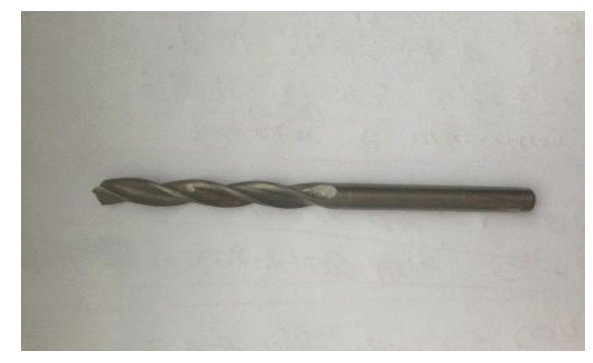

The time to drill a hole with a depth of $19(\mathrm{~mm})$ was 0.2 seconds. The durability of the drills, determined by wear, which increases the drilling power twice, amounted to 60,000 holes. The roughness of the treated surface is class $8(\mathrm{RA} \leq 0.63)$. Accuracy increased to 1 quality. The deviation from the non-roundness is less than 2 microns. The experiments were carried out without the use of lubricating coolant coolant. Processing of the poured apertures, deployment from F6mm, to F8mm, special scanning is carried out

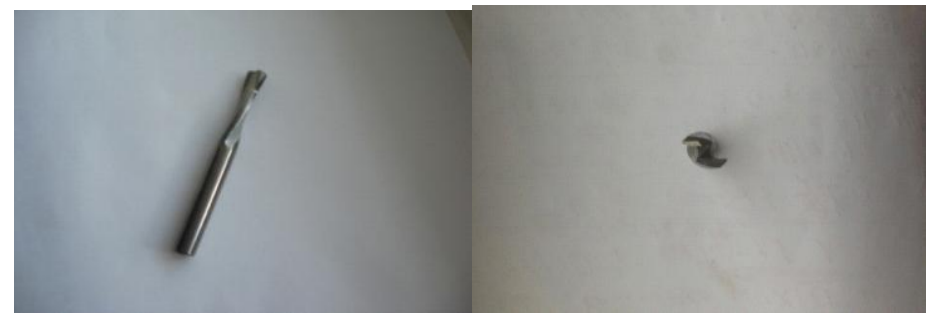

Deployment time to a depth of $19(\mathrm{~mm})$ was $0.2 \mathrm{sec}$. The resistance of the reamer, determined by wear, which increases the drilling power twice, was 500,000 holes. The roughness of the treated surface is class 9 (RA $\leq 0.32)$. The accuracy increased to 2 quality. The deviation from the nonroundness is less than 2 microns. The experiments were carried out without the use of lubricating coolant coolant.

In the same laboratory, the operation of milling flat surfaces of samples from cast aluminum alloys of the brands: AK6M2, US 319 and US 380 was implemented;

Preliminary tests of a new cylindrical end mill with a diameter of $\mathrm{D}=16 \mathrm{~mm}, \mathrm{Zi}=2, \mathrm{~d} 0=8(\mathrm{~mm})$, from the material VK8 showed a stable possibility of removing the pass allowance of $1 \mathrm{~mm}$ with a feed $\mathrm{Sm}$ $=9000(\mathrm{~mm} / \mathrm{min})=150(\mathrm{~mm} / \mathrm{sec})$.

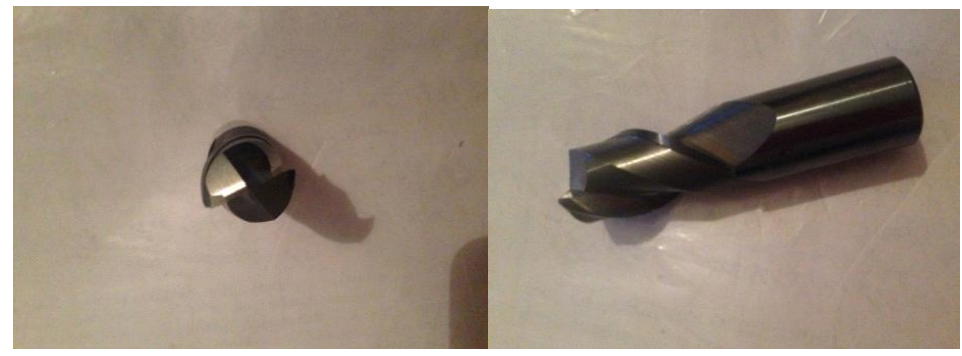


The roughness of the treated surface was $\mathrm{RA} \leq 0.16$ microns. The cutters worked until wear on the back face $\mathrm{h}=3 \mathrm{mkm}$, passing the cutting path $\mathrm{L}=60 \mathrm{~km}$. Wear on the front face was not detected. (The experiments were carried out without the use of lubricating coolant coolant).

\section{MOLYBDENUM TREATMENT}

Drilling a small diameter hole from F1 to F0. $5 \mathrm{~mm}$ to a greater depth $(\mathrm{h}=10-15 \mathrm{~mm})$ in molybdenum is a very difficult task. As a rule, this is a low-productivity process, accompanied by frequent breakage of drills. In 1999, this task was successfully solved at one of the enterprises of the space complex. Drilling holes F0. $5 \mathrm{~mm}$ in molybdenum to a depth of $10 \mathrm{~mm}$, two pen drills of hard alloy VK-8, without the use of coolant, allowed for continuous drilling with one drill to get 20 holes without breakage. The drilling time of one hole was 8 seconds.

\section{Treatment of Involute Surfaces of TeETH of Cylindrical WheEls.}

When searching for the most effective ways to form involute surfaces of cylindrical wheel teeth on a computer, several solutions were obtained. All of them were protected by patents of the Russian Federation: № 1378187, №1563056, №1098144. A method of processing teeth, protected by patent No. 1378187. It has the greatest practical interest, as for its implementation it is necessary and sufficient to have a gear milling machine, the table of which with the workpiece can rotate at a frequency of PST $100 \mathrm{rpm}$. such requirements are met by machines of PFAUTER and GLISSON.

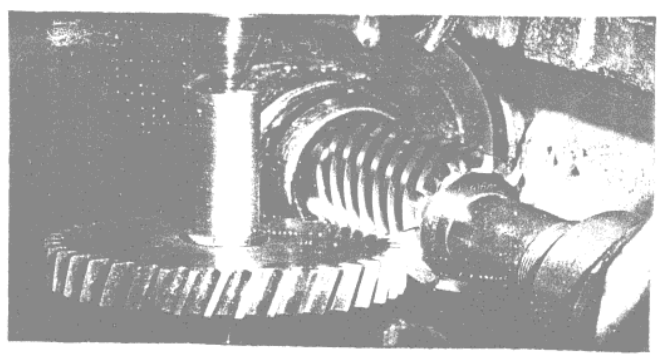

Rice.One

At the aggregate plant "KAMAZ" IN 1983-85. ( later until 1990. at ARMNIIMASH) carried out experimental processing of bevel gears gearbox $\mathrm{m}=4.25 ; \mathrm{Z}=46 ;=18 \mathrm{o}$ made of steel $35 \mathrm{X}$ after pre hot knurling, carried out at the mill vniimmash, with a hardness of HRC 28 and HRC 45. Processing was carried out on the gear milling machine "Module" GDR tool made of material P6M5 with the number of calls $\mathrm{N} 3=7$ using a special coolant having surface-active substances that allow to block adhesion setting at low cutting speeds, determining the active growth formation and setting of rubbing materials.

Removed allowance $\Delta=0,3 \ldots 0,4 \mathrm{~mm}$ on the side of the tooth with the width of the crown. $\mathrm{In}=30 \mathrm{~mm}$. cutting Modes that could be implemented were defined: $\mathrm{nu}=300 \mathrm{rpm}$; Sok=1.52 mm / Rev.count; $\mathrm{nk}=\mathrm{nuN} 3 / \mathrm{Zk}=45 \mathrm{rpm}$. This allowed one processing cycle in 20 seconds, which was confirmed by timing. The deviation from the theoretical involute was $1(\mu \mathrm{m})$ ! The experiments were achieved a high performance finishing gear treatment, removing the seam allowance to $0.5 \mathrm{~mm}$ on the side, one loop was less than $20 \mathrm{C}$. and was brought to $11 \mathrm{~s}$ The increase in hardness from HRC 28 to HRC 45 on the nature of cutting and the dynamics of the test did not make any visible changes.

A new method of gear processing of high-precision cylindrical wheels with a special tool has been developed and prepared for testing.

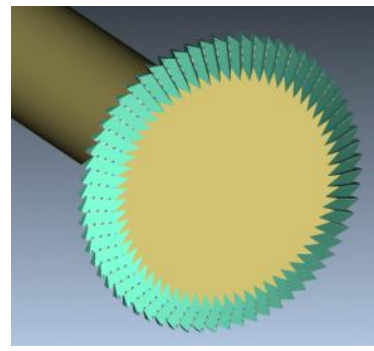

Boron milling cutter for milling involute profiles with deviations from the theoretical involute $\Delta \leq 1 \mathrm{mkm}$ 
The estimated cutting time of the cylindrical wheel module $m=1$, the number of teeth $\mathrm{Z}=37$ is less than $1.4 \mathrm{~min}$ !

\section{Processing of High-Hardness, Hardened Materials}

Sample material U8 high carbon steel. Hardness NRSE $\geq 65$. General purpose end mill tool, diameter $\varnothing 8 \mathrm{~mm} . \mathrm{Z}$ and $=4$. Material VK6 coated with Ti-AL-N (aluminitride). Before coating, the shape of the cutting edges changed. The cutter worked until wear on the back face $h=7 \mathrm{mkm}$, passing the cutting path $\mathrm{L}=10 \mathrm{~km}$. Wear on the front face was not detected. Roughness of the treated surface (RA $\leq 0.16$ microns).

\section{CONCLUSiON}

The use of both known, standard tools, and newly designed at the design cutting modes allows you to increase their resource by an order of magnitude, and also eliminates the formation of defects associated with grinding. On the basis of the basic laws of the pulse cutting theory, many works have been implemented in production.

\section{LITERATURE}

[1] Komarov V. A., Increase of efficiency of technological processes on the basis of improvement of processing of cutting. M: From-in MGTU them. N. E. Bauman, 2002.

Citation: Komarov V. A, (2019)" Innovations in Machining”, International Journal of Modern Studies in Mechanical Engineering, 5(4), pp. 1-4. DOI: http://dx.doi. org/10.20431/2454-9711.0504001

Copyright: (c) 2019 Authors, This is an open-access article distributed under the terms of the Creative Commons Attribution License, which permits unrestricted use, distribution, and reproduction in any medium, provided the original author and source are credited. 